\title{
Selección de herramientas web para la creación de actividades de aprendizaje en Cibermutua
}

\author{
Web tools selection in order to create learning activities in Cybermutua
}

\author{
Clara Patricia Avella-Ibáñez ${ }^{1}$ \\ Erika María Sandoval-Valero \\ Carmenza Montañez-Torres ${ }^{3}$
}

Recibido: febrero 21 de 2017

Aceptado: junio 29 de 2017

\section{Resumen}

Ciber-mutua es un ciber-museo desarrollado para el Museo Territorial de los Andes Nororientales (Mutua), el cual se proyectó como un espacio para conocer y explorar las diferentes realidades urbanísticas, patrimoniales y territoriales de la región centro-oriental de Colombia, coadyuvando en la recuperación del patrimonio cultural y urbano de la ciudad de Tunja, Colombia. Con el fin de reforzar el conocimiento expuesto en el ciber-museo y generar interés entre sus usuarios, se crearon actividades digitales de aprendizaje que hacen uso de herramientas web libres. Este artículo enfatiza en el proceso investigativo llevado a cabo en la selección de herramientas web para la creación de las actividades digitales de aprendizaje en el ciber-museo, exponiendo los beneficios e inconvenientes que se presentaron durante este proceso.

Palabras clave: aprendizaje, museo, ciber-museo, patrimonio cultural, software didáctico.

\begin{abstract}
Cibermutua is a cyber-museum developed for the Territorial Museum of the Northeastern Andes (Mutua), wich was designed as a space to know and explore the different urban, patrimonial and territorial realities of the Central-Eastern region of Colombia, contributing to the recovery of the cultural and urban heritage of the city of Tunja (Boyacá, Colombia). In order to reinforce the knowledge exhibited in the cyber-museum and generate interest among its users, digital learning activities were created that make use of free web tools. This article highlights the research process carried out in the selection of web tools for the creation of digital learning activities in the cybermuseum, presenting the results obtained during this process.
\end{abstract}

Keywords: learning, Museum, cyber-museum, cultural heritage, teaching software.

$1 \quad$ Ingeniera de Sistemas, Magíster en Ingeniería de Sistemas y Computación, Universidad de Boyacá, Colombia. E-mail: cpavella@uniboyaca.edu.co

2 Ingeniera de Sistemas, Magíster en Entornos Virtuales de Aprendizaje, Universidad de Boyacá, Colombia.E-mail: erisandoval@uniboyaca.edu.co

3 Ingeniera de Sistemas, Magíster en dirección estratégica de Tecnologías de la Información, Universidad de Boyacá, Colombia. E-mail: carmenzamt@uniboyaca.edu.co

Rev.investig.desarro.innov, 8(1), julio-diciembre de 2017, XX-XX. ISSN: 2027-8306 


\section{Introducción}

Los museos se centran esencialmente en conservar, investigar, difundir, comunicar, exponer y exhibir el patrimonio histórico y cultural de la humanidad (Acle-Mena, Villalobos-Abrego, \& Herrera-López, 2016). Adicionalmente, con el paso del tiempo estas funciones han ido evolucionando, de tal manera que actualmente se destaca el ofrecimiento en la Web, de compendios de documentación de carácter cultural de diversas épocas, que pueden ser consultados por las generaciones venideras (Álvarez-Meneses, 2013).

Los museos virtuales, por su parte, suelen hacer uso de actividades interactivas con el fin de buscar la apropiación del conocimiento por parte de la sociedad, y así garantizar que los elementos culturales, patrimoniales o territoriales expuestos sean asimilados por los usuarios (Elisondo, \& Melgar, 2015). En este sentido, los museos virtuales poseen herramientas como bibliotecas, archivos visuales, laboratorios y talleres, para involucrar a los usuarios en los diferentes escenarios culturales que se pretenden dar a conocer (Najar-Sánchez, Rincón, \& Camargo, 2014).

El Museo Territorial Urbano de los Andes Nororientales (Mutua) es un espacio de investigación y divulgación que, desde 2007, explora realidades urbanísticas, patrimoniales y territoriales de la región centro-oriental de Colombia. El principal propósito de Mutua es reflexionar acerca de la evolución de ciudades y municipios, la manera como sus habitantes conviven con el territorio y lo transforman, el valor de las expresiones culturales, el significado y la importancia patrimonial material e inmaterial, reconocido u oculto para la humanidad. Otros propósitos de Mutua incluyen el impulsar acciones de recuperación, preservación y gestión de diversos bienes, además de la conformación de una colección integrada por objetos representativos de los fenómenos que allí se estudian (Cibermutua, 2015).
EnMutuasepropusoeldesarrollodeuncibermuseo, materializado con el nombre de Cibermutua, el cual permite a los visitantes, realizar recorridos por sitios e historias que permiten conocer más sobre los Andes Nororientales de Colombia y así reflexionar sobre sus valores patrimoniales. Cabe resaltar que la población objeto del cibermuseo se centra en personas mayores de 14 años, deseosas de conocer información de patrimonio difuso y que tengan habilidades en el uso de Internet.

Antes de iniciar la construcción del cibermuseo, se identificaron algunos elementos de patrimonio urbano difuso ubicados en la ciudad de Tunja, Colombia, como: El Aeropuerto Gustavo Rojas Pinilla, los Silos y la Normal de Varones, pertenecientes a la ruta de la modernidad; los puentes ubicados en la vía a Oicatá, los lavaderos de Fuente Chiquita y el monumento al trigo, clasificados en la ruta pétrea; y el barrio Libertador, catalogado en la ruta sur-urbana. Estos elementos de patrimonio difuso hacen alusión al "reconocimiento y la divulgación de testimonios y marcas referenciales inherentes a procesos urbanos e históricos registrados en Tunja, que, debido a su significado, pueden considerarse como patrimonio, aunque carecen de reconocimiento por parte de las autoridades" (Hidalgo-Guerrero, 2015). La selección de los elementos permitió la consolidación de la información sobre los mismos, en relación a: la historia, el valor patrimonial, arquitectónico y urbanístico, así como las imágenes fotográficas.

La construcción del cibermuseo contempló desde su concepción la inclusión de actividades de aprendizaje, consideradas un elemento necesario para generar interactividad e interés por los contenidos del material disponible. La finalidad del presente artículo es difundir el proceso investigativo que se llevó a cabo para determinar cuáles herramientas Web se consideraron más apropiadas para crear actividades didácticas en el cibermuseo Cibermutua, de manera que se cumpliera con el propósito de incentivar 
la interacción de los usuarios y afianzar los conocimientos expuestos en el proyecto.

El documento inicia con el marco teórico que muestra los conceptos relacionados con el desarrollo de la investigación. Luego se presenta la metodología empleada para la selección de herramientas, los resultados, su discusión $y$, finalmente, las conclusiones del proceso de investigación adelantado por el equipo pedagógico.

\section{Marco teórico y metodología}

\subsection{Los cibermuseos}

Los museos han evolucionado continuamente debido a diversas razones, entre las que destacan la dificultad de las personas para desplazarse a estos lugares, los desarrollos e innovaciones en el sector tecnológico, y al hecho de ser un espacio de estudio e investigación (Hernández, 1992). Lo anterior, ha conducido a que actualmente se apoye el desarrollo de recursos digitales para su reconocimiento y difusión, llevando a la aparición de museos virtuales y cibermuseos.

Según Carrozino y Bergamasco (2010), los museos son instituciones relativamente recientes, y solo desde mediados del siglo $\mathrm{XX}$, se considera como característica propia de los mismos, llegar a ser una herramienta privilegiada para la comunicación. Cuando se habla de nuevas tecnologías en los museos, se privilegia la tecnología visual, poniendo a la imagen en el centro de la comunicación; así mismo, se hace primordial que los usuarios puedan interactuar con los elementos del museo. Actualmente, los museos pueden ser un medio para apoyar la educación formal y el aprendizaje permanente no formal a lo largo de la vida, labor que ha sido impulsada con la aparición de Internet (Rivero-Grácia, 2009).

Además, muchos museos han evolucionado para ofrecer al público de Internet sus colecciones en formato digital e incluso han nacido museos totalmente virtuales, los cuales son considerados "una colección de objetos digitales relacionados lógicamente entre sí, compuesta mediante diferentes medios que, gracias a su capacidad de ofrecer conectividad y diferentes puntos de acceso, permite trascender los métodos tradicionales de comunicación e interacción con los visitantes... no tienen una ubicación o espacio real, sus objetos y la información relativa a ellos pueden diseminarse por todo el mundo" (Schweibenz, 2004).

Los cibermuseos son un medio digital con narrativas propias, que presentan una evolución del museo tradicional e incluso son una variante del museo virtual, pues no se centran exclusivamente en el uso de la tecnología para virtualizar las colecciones (Escandón, 2015). Cibermutua es un Cibermuseo que permite reconocer el patrimonio urbano difuso de Tunja, siendo este último, un ejercicio proyectual creativo aplicado a un objeto sobre el que, por su esencial consideración de bien patrimonial, se propicia su conservación (Díaz et al, s.f.).

Muchos museos virtuales, con el fin de lograr un aprendizaje significativo en sus usuarios, incluyen imágenes interactivas, guías interactivas animadas, juegos interactivos y herramientas Web 2.0, entre otros (Rivero-Grácia, 2009; CallejasCuervo, Meléndez-Alvarez, \& Cotes-Roa, 2010). Teniendo en cuenta lo anterior, se determinó que en Cibermutua se incluirían actividades didácticas interactivas a través del uso de multimedia, imágenes y texto, entre otros.

\subsection{Aspectos pedagógicos}

Los EVA (Entornos Virtuales de Aprendizaje), permiten realizar aprendizaje por parte del usuario, sin que exista una formalidad en la administración del espacio virtual; es decir, el visitante ingresa al cibermuseo, encontrando recursos que permiten la aprehensión de los elementos patrimoniales sin la rigurosidad de un espacio virtual académico formal. Esto debido a que en los EVA no es 
necesario realizar un registro ni seguimiento del proceso de aprendizaje, sino que su navegación es dada por el gusto del usuario por el material publicado para la adquisición de información.

Las actividades de aprendizaje en el EVA, tienen el propósito de desarrollar habilidades y destrezas frente a la descripción de cada uno de los elementos presentados en el cibermuseo, para lograr un mayor conocimiento del patrimonio urbano difuso de la ciudad de Tunja. Además, teniendo en cuenta que los museos se consideran sitios con fines educativos, en esta investigación fue necesario profundizar en teorías relacionadas con la didáctica y la creación de actividades de aprendizaje en EVA, las cuales se mencionan en los siguientes párrafos.

Como punto de partida se analizó el concepto de didáctica, considerado como el conjunto de técnicas por medio de las cuales se realiza enseñanza (Carvajal, 2009). Esto llevó a deducir que, en un EVA las técnicas empleadas para lograr el aprendizaje deben involucrar Tecnologías de la Información y las Comunicaciones, TIC. El uso de estas tecnologías permite que en el proceso de enseñanza - aprendizaje se obtengan ventajas comolas mencionadas por Henao y Ramírez (2012), a saber: cambios en la forma en que se lleva a cabo el aprendizaje, construcción de conocimiento y aprendizaje a ritmo individual; esto último gracias al control en la selección de los contenidos.

En los sitios Web con fines educativos, el usuario no puede ser un receptor pasivo; por ello es necesario generar entornos que promuevan su participación, la cual se puede conseguir a través de la interacción mediante diferentes actividades, como: ejercicios, simulaciones o cuestionarios, entre otros (Muñoz-Rojas, 2016; BuitragoGuzmán, 2014). Adicionalmente, estas actividades prácticas garantizan un aprendizaje satisfactorio, ya que facilitan el proceso de asimilación de los contenidos del sitio Web, por parte de los usuarios (González, 2005).
Cacheiro (2011) señala que, en el diseño de un EVA, una de las tareas es plantear actividades y tareas de distinto tipo que permitan reforzar los contenidos y su aplicación en diversas situaciones. Cuando se diseñan actividades para EVA, es importante escoger las herramientas correctas para su realización. La tendencia ha sido utilizar sistemas de administración del aprendizaje, LMS por sus siglas en inglés, basados en la Web, los cuales han incorporado sus propias herramientas para la creación de actividades (Torres-Ortíz, \& Duarte, 2016). Sin embargo, en la Web existe una gran variedad de herramientas, distintas a las ofrecidas por los LMS, que pueden utilizarse para el diseño de actividades de aprendizaje, las cuales también pueden incorporarse en distintos EVA (Hoic-Bozic, Holenko, \& Mornar, 2016).

\subsection{Metodología}

El equipo pedagógico se centró en la selección y utilización de herramientas Web para crear las actividades didácticas de cada uno de los elementos de patrimonio difuso que conforman el Cibermuseo, para lo cual se utilizó la siguiente metodología:

Etapa 1. Se inició con la búsqueda de herramientas libres que facilitaran la construcción de actividades didácticas apropiadas para la población objetivo y su incorporación en Cibermutua, teniendo en cuenta que este fue desarrollado con el gestor de contenidos Joomla.

Etapa 2. Una vez definidas las herramientas a utilizar, se revisaron los textos que se publicarían en el portal Web de Cibermutua, construidos para cada elemento de patrimonio difuso, con el fin de determinar el tipo de actividad apropiada para cada elemento, de forma que se diseñaron tres actividades para cada uno de ellos. Las actividades se incluyeron bajo la premisa de permitir la interacción de los usuarios con la plataforma, con el fin de que el Cibermuseo no se convirtiera en un sitio exclusivo para exposición de contenidos, sino que, adicionalmente, propendiera por 
la apropiación de la información presentada, característica imperiosa de un museo virtual (Domínguez-Brito, 2003).

Etapa 3. Cuando se terminó el diseño de actividades, se procedió a crearlas en los sitios Web específicos de cada herramienta y se obtuvo el código embebido para posteriormente incluirlo en el Cibermuseo.

Etapa 4. Una vez creadas las actividades, se incorporaron en el Cibermuseo y se realizó una evaluación de las mismas con estudiantes universitarios de la ciudad de Tunja. Esta evaluación permitió identificar el comportamiento de los usuarios frente a las actividades, con el fin de realizar los cambios necesarios.

\section{Resultados y discusión}

\subsection{Búsqueda de herramientas}

Uno de los objetivos del proyecto era la utilización de herramientas Web libres para la creación de las actividades didácticas. La selección de estas herramientas inició con la revisión de estudios comparativos, entre los cuales se destacan los descritos en la Tabla 1.

\begin{tabular}{l} 
Estudio \\
\hline $\begin{array}{l}\text { Generadores online de material } \\
\text { educativo (Larraz, 2014). }\end{array}$ \\
20 Herramientas para crear actividades \\
educativas interactivas (Las TIC y su \\
utilización en la educación, 2014)
\end{tabular}

40 herramientas para aplicar la metodología flipped classroom en el aula (Aulaplaneta, 2015).

\section{Descripción}

Este estudio está ubicado en el blog 'Cuaderno intercultural' y se actualiza con cierta frecuencia. Su creación se realizó en 2008 y su última actualización (hasta la fecha de presentación de este artículo), es de octubre de 2014. Las herramientas se presentan agrupadas por temas y ofrece una breve descripción de la finalidad de cada una.

Es un blog en el cual se describe la finalidad de cada herramienta, así como aspectos destacados de cada una. En algunos casos, menciona herramientas similares a las analizadas.

La pedagogía inversa, o flipped classroom, es una metodología educativa en la cual los alumnos adquieren los conceptos teóricos en casa, a través de la visualización de un video, una presentación o cualquier otro recurso; y después, en clase, resuelven sus dudas y trabajan de forma individual y colaborativa.

En este estudio se agrupan las herramientas de acuerdo con su propósito y se realiza una breve descripción de su finalidad.

Tabla 1. Estudios destacados de herramientas Web para crear actividades didácticas.

La selección de las herramientas de la tabla 1 se hizo eligiendo aquellas que cumplieran la mayor cantidad de los siguientes criterios:

- Generación de código embebido. Algunas herramientas en línea generan código HTML, sigla en inglés de HyperText Markup Language, el cual se puede incorporar fácilmente a sitios Web creados con gestores de contenido.

- Facilidad de creación de actividades didácticas para refuerzo del aprendizaje. Existen varias aplicaciones de software que permiten crear, con sencillez, espacios interactivos para reforzar el aprendizaje, sin que sea necesario tener un buen nivel de programación.

- Oferta de diferentes recursos para incluir en educación en línea. En Internet se encuentra un alto número de herramientas específicas para diseñar y crear actividades de aprendizaje, de manera que era importante seleccionar las que ofrecieran actividades diseñadas para educación online, ya que estas actividades 
contemplan en su diseño, aspectos específicos para reforzar el aprendizaje con medios electrónicos, también llamado e-learning (Mercado-Ramos, Zapata, \& Ceballos, 2015).

- Herramientas de uso libre, con ausencia de publicidad o publicidad controlable. Muchas herramientas online son de uso gratuito a cambio de que el usuario tenga acceso a publicidad. El uso de publicidad excesiva lleva a que en muchos casos el usuario le reste importancia a la actividad, es por ello que algunas ofrecen un costo bajo para contrarrestar este aspecto.

- Facilidad de uso e interfaz amigable. Algunas de las herramientas en uso son intuitivas y poseen guías para su buen manejo.

- Calidad gráfica e interactiva de las actividades generadas. Es importante tener en cuenta la calidad de los recursos generados con las herramientas, para seleccionar las que se caractericen por un diseño gráfico llamativo e interactividad.

- Opciones de inclusión de imágenes en los test. Por tratarse de actividades para un Cibermuseo, es importante tener en cuenta que incluir imágenes en las actividades didácticas, le permiten al usuario reconocer con mayor facilidad los elementos que se están valorando.

- Rapidez para cargar la actividad. Es importante que las herramientas utilizadas para el diseño de las actividades permitan que las mismas sean cargadas rápidamente, con el fin de que el usuario se sienta satisfecho con los tiempos de respuesta.

- Diseño adaptable a múltiples plataformas. Con el uso actual de diversos tipos de dispositivos para conectarse a la Web, es importante considerar herramientas que generen actividades didácticas que puedan visualizar dispositivos móviles y computadores personales, sin desmejorar su calidad y eficiencia.

Las herramientas preseleccionadas fueron objeto de prueba por parte del equipo pedagógico y los resultados de esta actividad se presentan en la Tabla 2. 


\section{Herramienta / URL}

Educaplay / http://www.educaplay. com/

Constructor 2.0 / http://www. constructor.educarex.es

Jigsawplanet / http://www. jigsawplanet.com

Goconqr / http://www.goconqr.com

\section{Descripción y análisis}

- Herramienta para la creación de actividades didácticas en cuanto a refuerzo y apropiación de aprendizaje.

- Ofrece diferentes recursos para e-learning, como: adivinanza, diálogo, ordenar palabras, relacionar mosaico, completar dictado, presentación, sopa de letras, colección, mapa interactivo, emparejamiento, test, crucigrama, ordenar letras, relacionar columnas y video quiz.

- Herramienta gratuita con publicidad, si no se quiere publicidad, debe pagarse la suscripción anual, la cual permite descargar la actividad como recurso flash o en código embebido HTML5.

- Brinda una ayuda para evaluar la calidad en el diseño de la actividad, de manera que, si no cumple con unas características mínimas, no deja publicar la actividad.

- Permite crear diferentes tipos de actividades didácticas: completar texto, ahorcado, descubrir parejas, sopa de letras, emparejamiento, señalar partes de una imagen y ordenar palabras, entre otras.

- Ofrece herramientas visuales modernas

- Genera código embebido sin publicidad

- Permite crear rompecabezas de diferentes tamaños

- Por medio del enlace generado por la herramienta se va directamente a la ejecución de la actividad.

- Permite crear mapas mentales, test (verdadero - falso, elección múltiple con única o con múltiples respuestas), fichas y apuntes.

- Genera código embebido además de permitir el acceso por enlace a URL.

- Puede incluirse imágenes en los test.

- Herramienta gratuita con publicidad, o a bajo costo, de suscripción si no se quiere publicidad.

- Al incluir la actividad no permite su uso inmediato, ya que obliga al usuario a registrarse o iniciar sesión.

Tabla 2. Herramientas seleccionadas para la creación de actividades didácticas en Cibermutua.

\subsection{Diseño y creación de actividades}

En esta etapa se tomaron los textos construidos para cada uno de los elementos de patrimonio difuso y se eligió el tipo de actividad didáctica, considerado más apropiado para evaluar su contenido. Las actividades seleccionadas para afianzar el aprendizaje y reconocimiento de los elementos del patrimonio difuso urbano, se centraron en recursos digitales como: rompecabezas, sopas de letras, crucigramas, videos, evaluaciones y localizadores gráficos, entre otros, ver figura 1. 
Mapa interactivo

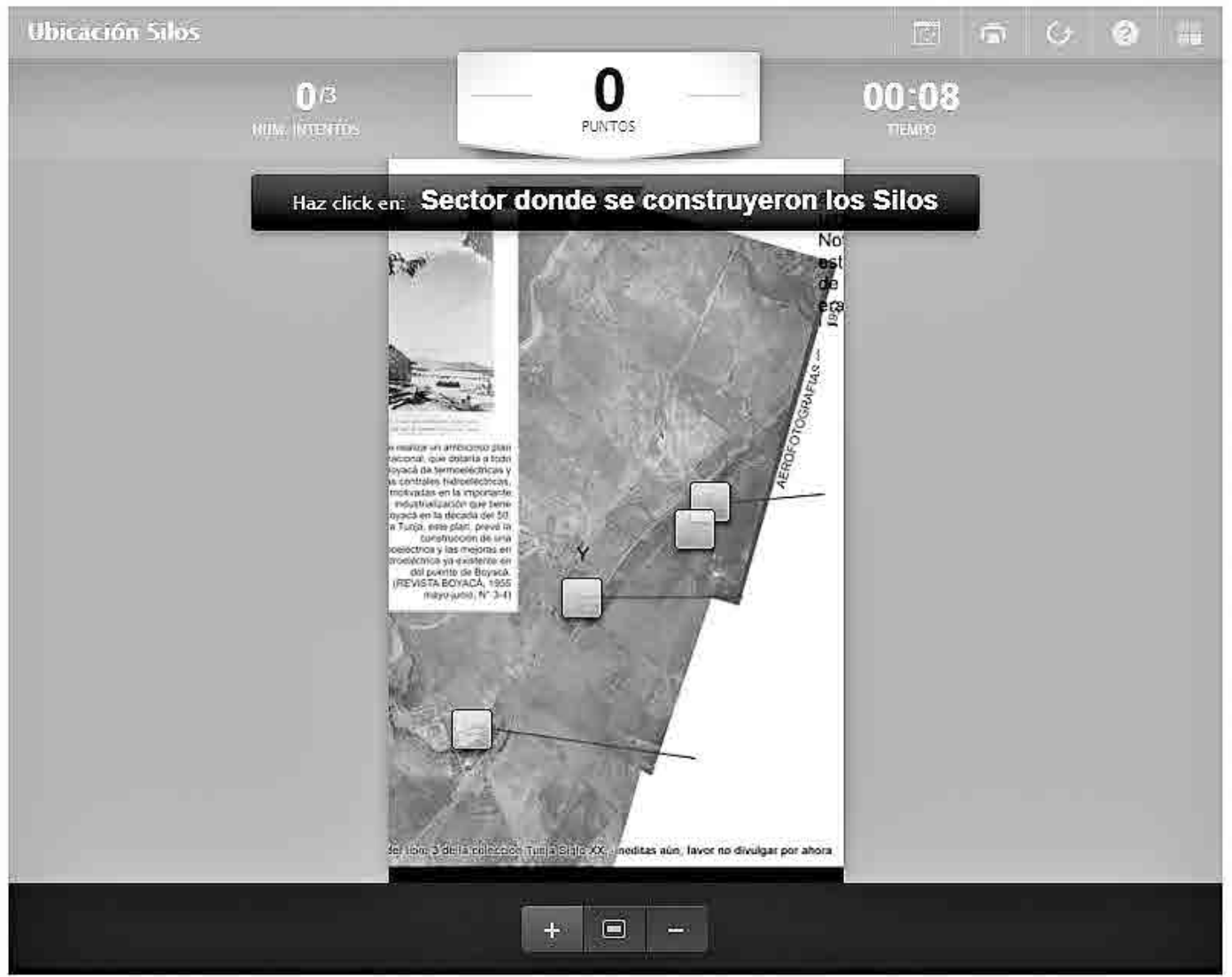

Figura 1. Pantalla actividad mapa interactivo Silos.

A partir de las actividades diseñadas por el equipo pedagógico, se identificaron aquellas consideradas más amigables para el desarrollo de la interacción y el aprendizaje del usuario, el cual es quien valora la información y el conocimiento que se encuentra en Cibermutua. Se elaboró el enunciado de cada actividad con sus alternativas de respuesta $y$, en las actividades de rompecabezas, ver figura 2 , se eligieron las imágenes consideradas más apropiadas. 


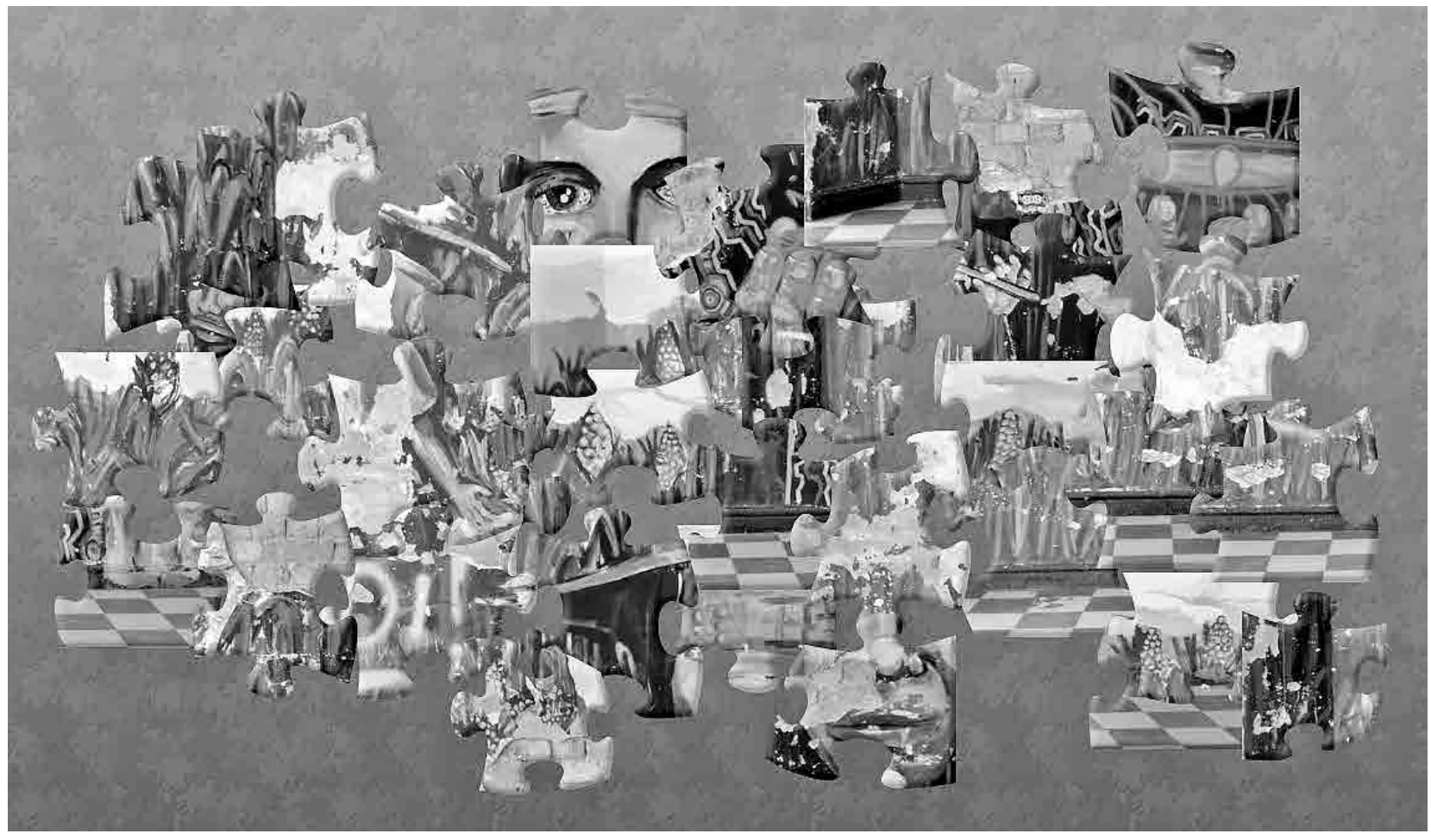

Figura 2. Pantalla del rompecabezas: Mural Normal de Varones.

Las herramientas Web elegidas ofrecen diferentes opciones para que los productos obtenidos sean publicados en espacios virtuales, como: código embebido, URL (Localizador Uniforme de Recursos), SCORM (Modelo de Creación y Empaquetado de Contenidos Educativos Digitales), el cual es un conjunto de estándares y especificaciones que permite crear objetos pedagógicos estructurados (Astudillo, Sanz, \& Willging, 2012). En el Cibermuseo se seleccionaron las siguientes opciones:

- Código embebido. Algunas herramientas generan código HTML el cual es copiado en el sitio Web destino para que se pueda apreciar la actividad.

- URL. Corresponde a la dirección Web del sitio donde fue creada la actividad, de manera que se crea un enlace con esta URL para que lleve al sitio donde está alojada, cuando el usuario hace clic sobre la misma.

En la Tabla 3 se presentan las actividades creadas e incluidas en Cibermutua para cada elemento de patrimonio difuso. 


\begin{tabular}{ccc}
\hline $\begin{array}{c}\text { Elemento urbano de patrimonio } \\
\text { difuso }\end{array}$ & Herramienta utilizada & Actividad creada \\
\hline Aeropuerto de Tunja & Educaplay & Test \\
& Constructor 2.0 & Emparejamiento \\
Silos & Educaplay & Adivinanza \\
& Educaplay & Test \\
& Educaplay & Mapa interactivo \\
Normal de varones & Jigsawplanet & Rompecabezas \\
& Educaplay & Ordenar palabras \\
& Educaplay & Completar \\
Puentes de piedra vía Oicatá & Jigsawplanet & Rompecabezas \\
& Constructor 2.0 & Arrastrar partes de imagen \\
& Constructor 2.0 & Arrastrar partes de imagen \\
Lavaderos Fuente Chiquita & Constructor 2.0 & Sopa de letras \\
& Educaplay & Sopa de letras \\
& Educaplay & Ordenar palabras \\
& GoConqr & Cuestionario verdadero - falso \\
Monumento al trigo & Jigsawplanet & Rompecabezas \\
& Jigsawplanet & Rompecabezas \\
& Educaplay & Adivinanza \\
& Educaplay & Crucigrama \\
& Educaplay & Completar \\
\hline
\end{tabular}

Tabla 3. Actividades didácticas incluidas en Cibermutua.

Luego de diseñar las actividades para cada elemento de patrimonio difuso, se realizó su creación en las herramientas Web seleccionadas: Educaplay, Constructor 2.0, Jigsawplanet y GoConqr, empleando para ello la cuenta de correo electrónico oficial del proyecto, lo cual es requisito para la utilización de estas herramientas.

Antes del lanzamiento del Cibermuseo, se realizaron pruebas sobre las actividades creadas que arrojaron algunos errores, como: preguntas redactadas sin la suficiente claridad $y$, en algunos casos, la inclusión de respuestas poco precisas que podrían confundir a los usuarios; estas actividades fueron corregidas por los autores de las mismas.
Las pruebas también permitieron identificar que no se estaba manejando el mismo estándar en la formulación de las actividades, ya que su creación fue distribuida entre los diferentes integrantes del equipo pedagógico. Este aspecto se corrigió, de manera que las actividades tuvieran un estándar unificado en cuanto a nombre de la actividad y descripción, para facilitar su reconocimiento por parte del usuario y su incorporación en el Cibermuseo.

\subsection{Evaluación de las actividades didácticas}

Para evaluar las actividades didácticas propuestas, se realizó la presentación pública del Cibermuseo en eventos organizados por la Red de Museos de Boyacá, a saber: Noche de los museos, realizada en 
Tunja, en mayo de 2015; Encuentro Departamental de Red de Museos públicos y privados de Boyacá, realizado en Villa de Leiva, en mayo de 2015.

- La evaluación de las actividades didácticas también se realizó mediante talleres de interacción de visitantes con el Cibermuseo. Se adelantaron 27 talleres, con 360 estudiantes universitarios de la ciudad de Tunja. Estos se llevaron a cabo en el período comprendido entre los meses de agosto y diciembre de 2015. El objetivo de estos talleres era identificar el comportamiento de los usuarios respecto a la interacción con los elementos de patrimonio difuso y sus actividades didácticas.

El resultado de la evaluación permitió identificar los siguientes aspectos en relación con las actividades didácticas creadas:

- La publicidad generada por la actividad creada en la herramienta Educaplay no es del gusto de la mayoría de los usuarios.

- Se considera una pérdida de tiempo tener que registrarse para realizar una actividad, este es el caso de GoConqr.

- Las sopas de letras y los rompecabezas son consideradas como las actividades más entretenidas por los usuarios.

- En algunas actividades no se formularon claramente las preguntas, a pesar de la revisión y corrección de las mismas, previo a la prueba con usuarios.

- Las respuestas de las sopas de letras y emparejamiento creadas con Educaplay, no se generan de forma aleatoria, así que se pierde el interés de los usuarios por repetir una actividad.
- Las actividades para completar párrafos son consideradas engorrosas y poco claras cuando incluyen textos muy largos.

- Algunas actividades no son claras en cuanto a lo que se debe realizar, tal es el caso de descubrir el personaje de una foto mediante pistas (Educaplay).

Como parte del análisis realizado por el equipo pedagógico, se encontró como inconveniente la ausencia del registro de los usuarios que realizaron las actividades y los resultados de las mismas. En el caso de las actividades que obligan a iniciar sesión o registrarse, se conservan los resultados por actividad, pero se presenta el inconveniente mencionado anteriormente, en cuanto a que los usuarios consideran una pérdida de tiempo realizar esta tarea de registro.

En cuanto a quitar la publicidad generada por algunas actividades, esto es posible siempre y cuando se pague por el uso de la herramienta. El pago por uso de herramientas como Educaplay da derecho a generar código embebido libre, sin embargo, se sigue presentando el inconveniente de no guardar el registro de visitantes y respuestas por cada actividad. Para que esta información se obtenga, el usuario debe ingresar con su usuario y contraseña, directamente en el sitio Web de esta herramienta.

\subsection{Discusión}

Desde los inicios del Cibermuseo, se reflejó la necesidad de que el portal Web se convirtiera en un espacio interactivo para generar interés en los usuarios y reforzar los contenidos expuestos en el museo, de manera tal que las actividades didácticas creadas forman parte de esta interacción, ya que no son los únicos elementos de interacción que ofrece el Cibermuseo. Por otra parte, las actividades permitieron que los usuarios mostraran su motivación para resolver la mayoría de las actividades incluidas en Cibermutua. Esto valida las teorías expuestas en cuanto a la 
importancia de la interactividad en los museos, mencionada por Rivero-Grácia (2009).

Otra razón para incluir actividades didácticas en el Cibermuseo, de acuerdo con Rivero-Grácia (2009), fue la intención de permitir que los usuarios reforzaran el conocimiento presentado, con el fin de propiciar el aprendizaje permanente no formal entre los usuarios. Sin embargo, por el hecho de no contar con los registros de los resultados de las actividades desarrolladas por los usuarios, no fue posible determinar si estas cumplieron con dicho fin. En este mismo sentido, tampoco se pudo comprobar que se hubiera dado un aprendizaje significativo por parte de los usuarios sobre los elementos de patrimonio difuso.

Es necesario incorporar actividades didácticas en los Cibermuseos que permitan la recopilación de los resultados de la interacción con las mismas por parte de los usuarios, esto con el fin de identificar si dichas actividades favorecen y enriquecen el aprendizaje; de lo contrario solo se puede afirmar que las actividades didácticas generan motivación hacia el uso del Cibermuseo.

En este sentido, si se quisiera disponer de información sobre la interacción pedagógica del usuario sobre la plataforma, en la actualidad se hace necesario redirigirlo para que se registre y/o inicie sesión en el sitio oficial que suministra la herramienta. Lo anterior lleva a recomendar que las actividades didácticas del Cibermuseo se elaboren con herramientas de desarrollo de software propio, a cambio del uso de herramientas Web libres.

\section{Conclusiones}

Al indagar sobre las herramientas Web disponibles para la creación de actividades educativas, se identificó que se han realizado estudios comparativos sobre las mismas, los cuales brindan pautas para su selección y ofrecen ayudas para su utilización; sin embargo, en relación con actividades para entornos virtuales abiertos con características específicas, es necesario hacer un estudio particular, determinando las necesidades a la medida y así evaluar la pertinencia de las herramientas para el sitio Web.

Todas las herramientas generadoras de actividades utilizadas en el proyecto, son pertinentes para fomentar el conocimiento a través de la interacción con usuarios. La herramienta más utilizada fue Educaplay debido a que se considera apropiada, ofreciendo ventajas, tales como: diversidad de actividades, interfaz gráfica amigable y facilidad de uso, tanto para creadores como para usuarios.

Con base en los resultados de la prueba piloto aplicada a los usuarios del Cibermuseo, es posible afirmar que los recursos digitales multimedia y las actividades didácticas, enriquecen no solo los contenidos expuestos, sino la interacción de los usuarios con el Cibermuseo; esto debido a que se observó un alto grado de motivación en los usuarios, por cumplir los retos de las actividades disponibles para cada elemento del Cibermuseo y por interactuar con los recursos multimedia.

La obtención de resultados precisos y cuantificables sobre la interacción de los usuarios con las actividades didácticas propuestas para los elementos expuestos en el Cibermuseo, no se puede determinar solo con la utilización de herramientas Web en línea para creación de actividades, sino que es necesario disponer de un producto de software desarrollado a la medida, con la funcionalidad de almacenar el ingreso y resultados de cada usuario en las actividades desarrolladas. Esto permitiría analizar los logros obtenidos por los usuarios, y determinar si se produjo aprendizaje significativo al interactuar con el Cibermuseo.

\section{Agradecimientos}

Los autores agradecen a la Universidad de Boyacá y a Colciencias, por financiar el proyecto: El Cibermuseo, un medio para reconocer el patrimonio urbano difuso de Tunja. 


\section{Referencias}

Acle-Mena, R. S., Villalobos-Abrego, C., \& HerreraLópez, B. (2016). Reposicionamiento del Barrio del Artista para aumentar su valor cultural-artístico en Puebla, México. Revista de Investigación, Desarrollo e Innovación, 6 (2), 109-116. Doi: http://doi. org/10.19053/20278306.4601

Álvarez-Meneses, T. (2013). La planificación turística: un aspecto clave para el desarrollo sostenible y regional de Boyacá. Revista de Investigación, Desarrolloelnnovación, 3(2), 101-110. doi:http://dx.doi.org/10.19053/20278306.2169

Astudillo, G. J., Sanz, C., \& Willging, P. A. (2012). Análisis de Compatibilidad entre Objetos de Aprendizaje basados en SCORM y LMS de Código Abierto. Conferencias LACLO, 3 (1).

Aulaplaneta. (2015). 40 herramientas para aplicar la metodología flipped classroom en el aula. Recuperado de: http://www.aulaplaneta. com/2015/05/12/recursos-tic/40-herramientaspara-aplicar-la-metodologia-flipped-classroomen-el-aula-infografia/

Buitrago-Guzmán, S. (2014). Relación entre la convergencia de mediosy la experiencia de usuario. Dos iniciativas creativas en Colombia. Revista de Investigación, Desarrollo e Innovación, 4 (2), 79-86. doi: http://dx.doi.org/10.19053/20278306.2958

Cacheiro, M. (2011). Recursos educativos TIC de información, colaboración y aprendizaje. PíxelBit. Revista de Medios y Educación. 39, 69-81. Recuperado de: http://e-spacio.uned.es/fez/eserv/ bibliuned:425-Mlcacheiro-5010/Documento.pdf

Callejas-Cuervo, M., Meléndez-Álvarez, L. F., Cotes-Roa, A. P. (2010). Desarrollo de aplicaciones móviles enfocadas al turismo en el departamento de Boyacá. Revista Virtual Universidad Católica del Norte, (29), 1-14. Recuperado de: http://www. redalyc.org/articulo.oa?id=194214466010
Carrozino, M. \& Bergamasco, M. (2010). Beyond virtual museums: Experiencing immersive virtual reality in real museums. Journal of Cultural Heritage, 11 (4), 452-458. Doi: 10.1016/j.culher.2010.04.001

Carvajal, M. (2009). La didáctica en la educación. Fundación academia de dibujo profesional. Recuperado de: http://www.fadp.edu.co/uploads/ ui/articulos/LA_DIDACTICA.pdf

Cibermutua. (2015). Cibermuseo de MUTUA - Museo territorial de los Andes Nororientales. Recuperado de: http://cibermutua.co

Díaz, C., Gumá, R., Rodríguez-Cid, J., Simancas, L., Torres, C., \& Cornadó, C. (s.f.). Nuevos usos para el patrimonio difuso. Escuela Técnica Superior de Arquitectura de Barcelona. Universidad Politécnica de Cataluña. Recuperado de: https://www.diba.cat/c/document_library/ get_file?uuid=452e51df-d35c-4590-b074c775ca6dae67\&groupld=7294824

Domínguez-Brito, L. A. (2003). Los museos en línea: un recurso educativo de los museos (Tesis de maestría). Universidad de Las Américas, Puebla, México. Recuperado de: http://catarina. udlap.mx/u_dl_a/tales/documentos/mdi/ dominguez_b_la/capitulo5.pdf

Elisondo, R., \& Melgar, M. F. (2015). Museos y la Internet: contextos para la innovación. Innovación educativa, 15 (68), 17-32. Recuperado de: http:// www.scielo.org.mx/scielo.php?script $=\mathrm{sci}_{-}$ arttext\&pid=S1665-26732015000200003\&Ing=es \&tlng=es.

Escandón, P. A. (2015). Cibermuseos, mediación comunicativa y apropiación. De los medios a los metamedios. Actas I Simposio de la Red Internacional de Investigación de Gestión de la Comunicación. Recuperado de: https:// delosmediosalosmetamedios.files.wordpress. com/2016/03/75-cibermuseos-mediaciocc81ncomunicativa-y-apropiaciocc81n.pdf 
González, M. (2005). Cómo desarrollar contenidos para la formación on line basados en objetos de aprendizaje. Revista de Educación a Distancia, III. Recuperado de: http://www.um.es/ead/red/M3/

Henao, O., \& Ramírez, A. (2012). ¿Cómo enseñar el área de lenguaje con un enfoque constructivista, utilizando en el aula un computador, un videoproyector e internet? Revista Educación y Pedagogía, 24 (62), 219-230.

Hernández, F. (1992). Evolución del concepto de Museo. Revista general de información y documentación, 2 (1), 85-97.

Hidalgo-Guerrero, A. (2015). Tres elementos modernos del patrimonio urbano difuso en Tunja, Boyacá. Territorios, 33, 13-32. Doi: dx.doi. org/10.12804/territ33.2015.01

Hoic-Bozic, N., Holenko, M. \& Mornar, V. (2016). Recommender System and Web 2.0 Tools to Enhance a Blended Learning Model. IEEE Transactions on education, 59 (1), 39-44. doi: http:// doi.org/10.1109/TE.2015.2427116

Larraz, R. (2014). Generadores online de material educativo. Cuaderno Intercultural. Recuperado de: http://www.cuadernointercultural.com/tic-tools/ generadores-online/

Las TIC y su utilización en educación. (2014). 20 Herramientas para crear actividades educativas interactivas. Recuperado de: http://www. ticeducacionec.com/2014/02/20-herramientaspara-crear-actividades.html
Mercado-Ramos, V. H., Zapata, J., \& Ceballos, Y. F. (2015). Herramientas y buenas prácticas para el aseguramiento de calidad de software con metodologías ágiles. Revista de Investigación, Desarrollo e Innovación, 6 (1), 73-83. doi: http://doi. org/10.19053/20278306.3277

Muñoz-Rojas, H. A. (2016). Mediaciones tecnológicas: nuevos escenarios de la práctica pedagógica. Praxis \& Saber, 7 (13), 199-221. doi: http://dx.doi.org/10.19053/22160159.4172

Najar-Sánchez, O., Rincón, M. E., \& Camargo, E. M. (2014). Materiales educativos computarizados como apoyo al turismo en Tunja. Pensamiento y acción, 0 (19), 107-117. Recuperado de: http:// revistas.uptc.edu.co/revistas/index.php/ pensamiento_accion/article/view/3047

Rivero-Grácia, M. (2009). Museos y didáctica on-line: cinco ejemplos de buenas prácticas. Recuperado de: http://www.academia.edu/download/40135025/ Riverohermes.pdf

Schweibenz, W. (2004). El desarrollo de los museos virtuales. ICOM - International Council of Museums. Recuperado de: http://icom.museum/fileadmin/ user_upload/pdf/ICOM_News/2004-3/SPA/ p3_2004-3.pdf

Torres-Ortiz, J. A., \& Duarte, J.E. (2016). Los procesos pedagógicos administrativos y los aspectos socioculturales de inclusión y tecno-pedagogía a través de las tendencias pedagógicas en educación a distancia y virtual. Revista de Investigación, Desarrollo e Innovación, 6 (2), 179-190. doi: http:// doi.org/10.19053/20278306.4606 